\title{
Hot monkey, cold reality: surveying rainforest canopy mammals using drone-mounted thermal infrared sensors
}

\author{
Roland Kays ${ }^{\mathrm{a}, \mathrm{b}, \mathrm{c}}$, James Sheppard ${ }^{\mathrm{d}}$, Kevin Mclean ${ }^{\mathrm{e}}$, Charlie Welch ${ }^{\mathrm{d}}$, Cris Paunescu , \\ Victor Wang ${ }^{d}$, Greg Kravit ${ }^{d}$ and Meg Crofoot ${ }^{c, e}$ \\ aiodiversity Lab, North Carolina Museum of Natural Sciences, Raleigh, NC, USA; ${ }^{b}$ Department of Forestry \\ and Environmental Resources, North Carolina State University, Raleigh, NC, USA; 'Smithsonian Tropical \\ Research Institute, Balboa, Republic of Panama; ${ }^{d S a n}$ Diego Zoo Global, San Diego Zoo Institute for \\ Conservation Research, Escondido, CA, USA; eDepartment of Anthropology, University of California Davis, \\ Davis, CA, USA
}

\begin{abstract}
Animals of the rainforest canopies are often endangered by deforestation or hunting but are difficult to survey and study because of the inaccessibility of the treetops, combined with the visual camouflage of many species. Drone-based thermal sensors have the potential to overcome these hurdles by rapidly scanning large forested areas from above, detecting and mapping wildlife based on the contrast between their warm body temperatures and the cool tree canopies. We tested this concept by flying a drone-mounted thermal infrared radiometric sensor over the wildlife-rich rainforests of Barro Colorado Island, Panama. Arboreal mammals had body temperatures around $27^{\circ} \mathrm{C}$ and were conspicuous in the thermal infrared imagery at night and early morning when the forest canopy was cool $\left(23-25^{\circ} \mathrm{C}\right)$, but were difficult to detect by mid-morning, by which time the direct sunshine had heated up canopy vegetation to over $30^{\circ} \mathrm{C}$. Species were difficult to identify from thermal infrared imagery alone, but could be recognized from synchronized visual images taken during the daytime. Simultaneous drone and ground-based surveys of the same area proved that the aerial thermal camera did detect highcanopy species missed by the terrestrial observer, but that substantially more animals were detected by the human than by the drone. Because animal detection was so much better at night, when species ID was difficult, we suggest that future work could combine automated detection of animals from thermal infrared imagery with flash photography or IR illumination to enable species ID during nocturnal surveys. We conclude by discussing various logistical challenges that limit the utility of drone-based thermal infrared today, but that could be overcome by continued improvement of technology and collaboration with permitting agencies.
\end{abstract}

\section{Introduction}

Tropical forest canopies remain one of the least explored habitats on earth because they are difficult to access (Lowman 2009). While canopy cranes and walkways are a solution 
for some botanical or insect studies, larger tree-dwelling animals move too far to be studied effectively from such stationary perches. Thus, most work with canopy mammals has been conducted by ground-based observers, craning their necks upward to record data from glimpses of animals through the foliage (Kays and Allison 2001). Surveys of canopy mammals are necessary for evaluating the conservation value of forests and quantifying the risks to specific species (Sampaio et al. 2010), but traditional groundbased transects require extensive effort, miss small or cryptic species, and are almost never done for nocturnal species (Bowler et al. 2016). Recent efforts to survey tree canopies with camera traps have provided more comprehensive data on the arboreal fauna, but are still limited in geographic scale because of the time and effort it takes to climb trees and check the cameras (Gregory et al. 2014; Bowler et al. 2016).

Drones (a.k.a. unmanned aerial systems) provide a top-down view of forests and have great promise to expand the spatial scale of canopy surveys in ways that would be useful for studies of vertebrate ecology. Imagery from drones has been useful for surveys of animals in open areas; for example, counting water birds (Hodgson et al. 2018), crocodiles (Thapa et al. 2018), and deer (Chretien, Theau, and Menard 2016). These techniques have not been widely applied for canopy animals, presumably because it is too hard to visually detect animals in trees from standard aerial imagery. The primary arboreal wildlife application of drone imagery to date has been to search for treetop nests of great apes, which was only moderately successful, finding just $17 \%$ of known orangutan (Pongo abelii, Wich et al. 2016) and 8\% of known chimpanzee (Pan troglodytes, van Andel et al. 2015) nests. Most drone-based surveys of wildlife have relied on sensors that collect imagery only in visual wavelengths, and thus only work during the day and are often inefficient at finding animals that have evolved visual camouflage to hide from predators (Longmore et al. 2017).

Thermal imaging has long been viewed as a potentially useful technology to increase the detection of wildlife (Croon et al. 1968). However, it has not become a popular tool because the technology was expensive, as were the aircraft needed to get aerial footage (Haroldson et al. 2003), and because it was not useful in detecting animals underneath leafed-out forest canopies (Potvin and Breton 2005). Recent technological advances in thermal infrared sensors, coupled with their miniaturization for drones and reduction in price, has resulted in renewed interest in this technology for wildlife surveys. Seymour et al. (2017) found thermal imagery useful for counting seals hauled out on beaches, while Witczuk et al. (2017) showed that terrestrial ungulates could be identified in both leafless deciduous forests and coniferous forests, but that the animals were most detectable when the background environment was the coolest, especially at night or in early morning. The work of Witczuk et al. (2017) in Poland and Goodenough et al. (2018) in South Africa both noted the difficulty of identifying animals to species using only the thermal imagery. To date one study has used drone based thermal imagery to find arboreal animals, detecting all six koalas (Phascolarctos cinerus) residing in a small enclosed forest of a rehabilitation center (Gonzalez et al. 2016).

The rainforest canopy fauna offers unique challenges not encountered by these previous drone applications. First, the thick leaf cover could block the thermal signature of the animals if they are not sitting at the very top of a tree. Second, for species more mobile than koalas, the noise of the drone could scare them back down towards the ground where they would be further blocked by leaves. Third, species identification 
might be difficult, depending on the quality of the images acquired. To evaluate the importance of these factors, we conducted tests of the ability of a drone with thermal and visual sensors to detect and identify canopy mammals in a tropical rainforest. We conclude by identifying strengths and weaknesses of the drone-based thermal imagery approach as a real-time survey tool and suggest paths for improvements and future directions.

\section{Materials and methods}

Our study was conducted at the Smithsonian Tropical Research Institute's field site on Barro Colorado Island, Panama ( $\left.\mathrm{BCl}, \mathrm{N} 9.16514^{\circ}, \mathrm{W}-79.8369^{\circ}\right) . \mathrm{BCl}$ is a 1560 ha island of semi-deciduous lowland tropical forest that was isolated from the mainland in 1914 when the Chagres River was dammed to form Lake Gatun and the Panama Canal. It is home to a diverse community of arboreal and scansorial species that might be detectable in a thermal imaging survey of the canopy, including four primates (Ateles geoffroyi, Alouatta palliate, Cebus capucinus, and Saguinus geoffroyi), two procyonids (Potos flavus, Nasua narica), two sloths (Bradypus variegatus, Choloepus hoffmanni), a porcupine (Coendou rothschildi) and an anteater (Tamandua mexicana). Drone flights were conducted with the authorization of the Panama Autoridad Aeronautica Civil, Direccion de Navegacion Aerea, Departamento de Gestion de Trasito Aereo, permit \# 0269-18.

The drone was a customized DI Matrice 600Pro ${ }^{\circledR}$ powered by 129.96 Wh lithium ion batteries that enabled flight times of $25-30 \mathrm{~min}$. The drone had an integrated sensor suite consisting of a gimbal-mounted DJI Zenmuse XT® ${ }^{\circledR}$ V2.0 FLIR uncooled thermal infrared radiometric sensor with $17 \mu \mathrm{m}$ pixel pitch, $7.5-13.5 \mu \mathrm{m}$ spectral band, $640 \times 512$ pixel resolution at $30 \mathrm{~Hz}$ framerate and a $13 \mathrm{~mm}$ lens with a $45^{\circ} \times 37^{\circ}$ field of view and $8 \mathrm{x}$ digital zoom. The use of thermal infrared alone does not always ensure reliable and consistent detection and identification of wildlife (Chretien, Theau, and Menard 2016). Therefore, we paired the thermal imaging sensor with a fixed Canon EOS 5DS ${ }^{\circledR}$ RGB camera with a 50.6 Megapixel, full-frame CMOS sensor using a Canon EF $40 \mathrm{~mm}$ $\mathrm{f} / 2.8 \mathrm{STM}$ lens to acquire visual imagery at the same site and time as the thermal imagery. Both sensors were angled straight down at the ground in a nadir view during surveys.

The thermal imaging and RGB sensors were programmed to capture data simultaneously when triggered manually by the operator or autonomously when reaching waypoints during automated transect survey flights. The remote video feed from the thermal imaging sensor to the drone operator enabled real-time detection and monitoring of canopy wildlife as well as the capture of static imagery in radiometric JPEG and TIFF format with embedded thermal information. Static imagery from the thermal and RGB sensors was corrected to $\sim 4 \mathrm{~cm}$ during post-processing using an EMLID Reach ${ }^{\circledR}$ RS RTK GNSS receiver.

Drone survey flights were planned and conducted using ArcGIS ${ }^{\circledR} 10.6$ (Esri Inc. 2018) and the DJ Go ${ }^{\circledR}$, DJI GS Pro ${ }^{\circledR}$ and Pix4D Capture ${ }^{\circledR}$ apps. Thermal imaging sensor data was processed and summarized using the FLIR Tools $+{ }^{\circledR}$ software. We scanned for canopy animals using the 'white-hot' and 'black-hot' false color palette options offered by the FLIR Zenmuse display which provide the best default settings for improving detectability of specific landscape features when surveying environments with small temperature variations. We also improved the ability of the FLIR sensor to detect canopy mammals by 
calibrating custom isotherms using external human body temperature ranges measured against background rainforest temperatures (lower $=27.8^{\circ} \mathrm{C}$, upper $=32.4^{\circ} \mathrm{C}$ ).

We conducted drone surveys of the rainforest across an area of approximately 50 hectares between the 19 - 25 February 2018 during the late $\mathrm{BCl}$ dry season, when leaf cover is at its minimum. Given the importance of having a thermal contrast between study animals and the background environment, we needed to determine how the thermal environment of the rainforest changed throughout the day to identify the optimal time for conducting surveys. Hence, we conducted heat-mapping surveys of the temperature profile of the rainforest using the autonomous mission system to characterize patterns in the emissivity and ambient background temperatures of the rainforest from 6:30 to 20:30. We conducted opportunistic surveys of canopy wildlife by manually flying preprogrammed gridline transects and pausing to follow any detected animals. Most of our flights in search of animals were conducted at night and during the early morning (before 8:30) when the trees were coolest. We recorded meteorological conditions during drone flights at the launch site using a Kestrel ${ }^{\mathrm{TM}}$ model 5500 weather meter and ambient light levels using a TES TM model 132 datalogging light meter.

We conducted two tests of the ability of the drone to detect and identify canopy animals compared to traditional ground-based methods. We flew the drone at $80 \mathrm{~m}$ altitude along a 12-hectare survey grid of contiguous transects spaced $80 \mathrm{~m}$ apart beginning at dawn (6:00) on two consecutive days. An experienced biologist with binoculars walked a $1.5 \mathrm{~km}$ forest trail within the same survey area contemporaneously with the drone. This design allowed both the drone and the person to visually survey approximately the same area of continuous forest. Each aerial survey took $\sim 25$ minutes and each ground survey took 35 minutes. The locations and numbers of animal sightings from the surveys were compared to determine whether the drone-based method for detecting animals had an advantage over the ground-based approach.

\section{Results}

Our drone-based thermal imaging sensor enabled us to detect and remotely observe three species of arboreal mammal in complete darkness ( $<0.1 \mathrm{~W} \mathrm{~m}^{-2}$ light): 1) mantled howler monkeys (Alouatta palliata); 2) black-handed spider monkeys (Ateles geoffroyi) and; 3) kinkajous (Potos flavus). We observed troops of howler monkeys moving across the canopy and at least five kinkajous foraging individually on nectar from the flowers of a large balsa tree (Ochroma pyramidale) (Figure 1, Video-1). The mammals were easily seen in the thermal imagery during the night and early morning when the canopy had cooled, but they were less obvious during the daytime when direct sunlight heated up the leaves. Upper canopy temperatures recorded by the thermal sensor ranged from $16^{\circ}$ $\mathrm{C}$ for shaded leaves at 5:30 to $43^{\circ} \mathrm{C}$ for bare branches at 12:15. The upper canopy warmed up rapidly after dawn under intensifying insolation, with canopy temperatures peaking around 12:00 - 14:00. Consequently, the temperature range between rainforest ambient temperatures and canopy wildlife increasingly narrowed following sunrise, which reduced the efficacy of the thermal sensor to differentiate the signature of animals from that of the background environment (Figure 2).

Maximum external temperatures recorded by the thermal sensor for canopy mammals were $27{ }^{\circ} \mathrm{C}$ for a kinkajou at $20: 37$ and $53{ }^{\circ} \mathrm{C}$ for a howler monkey at midday 


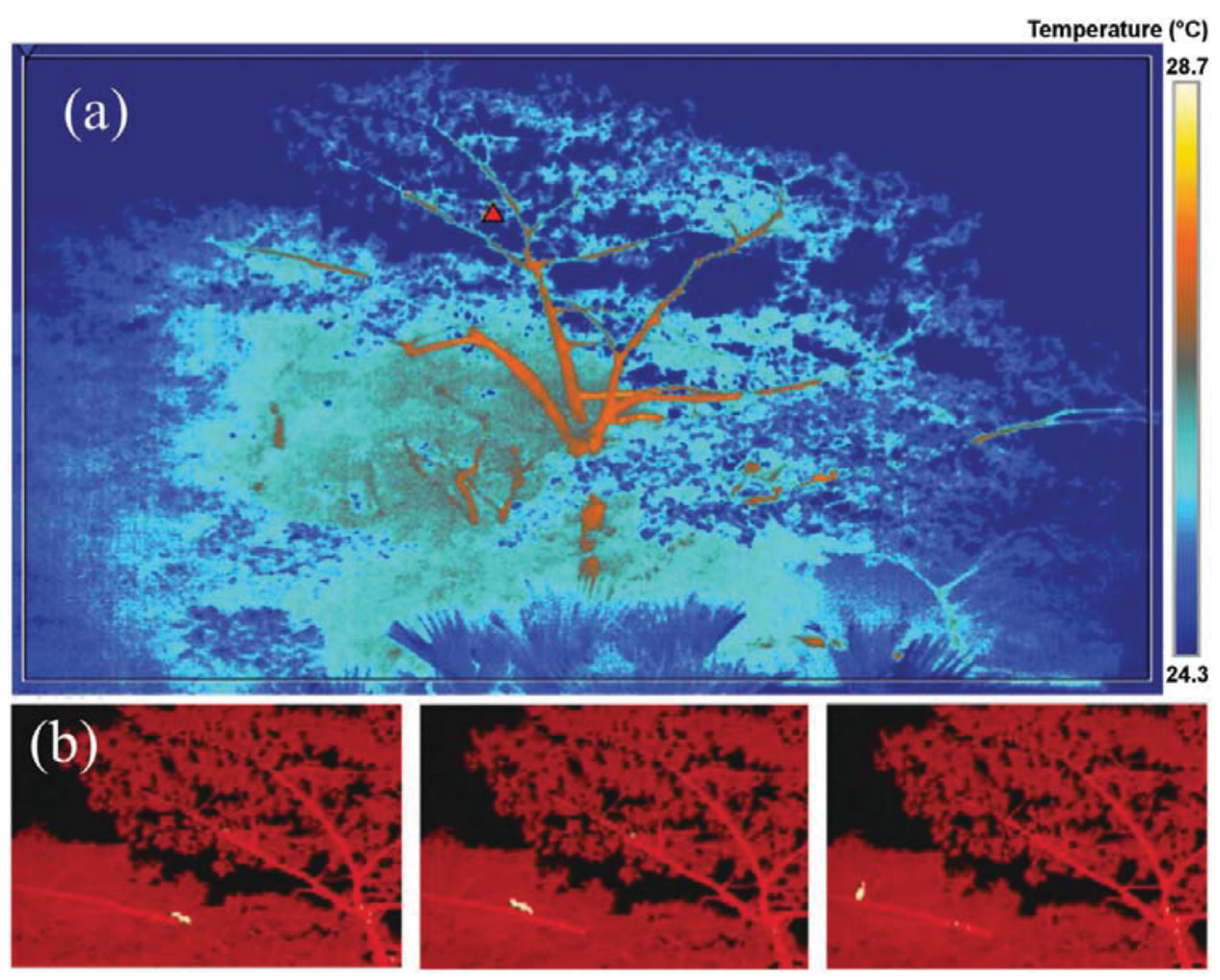

Figure 1. (a) Thermal infrared capture of a balsa tree (Ochroma pyramidale) taken from a drone at a side angle at 20:37. A bounding box can be placed over the thermal data feed during flight to automatically track the location of the highest temperature pixels and aid in animal detection. A red triangle shows the warmest site $\left(28.7^{\circ} \mathrm{C}\right)$ in the white bounding box and the location of a kinkajou in the tree branches. ( $b$, left to right) Thermal isotherms tuned to the body temperature range of target species can aid in separating the thermal signature of animals from that of the ambient environment. This sequence of infrared captures shows a kinkajou (white pixels) moving across a branch in the same balsa tree while feeding on nectar provided by the tree's flowers that open in the evening. Although the pixel resolution of thermal imaging sensors is low, experienced biologists can identify species such as kinkajous based on their size, general morphology and distinctive movement behaviors.

(Table 1). Presumably the monkey's dark hair contributed to this very high temperature, which made the howler monkeys' thermal profiles distinct from the background rainforest temperature even during the heat of the afternoon. Typical external temperatures for canopy mammals were within the range of $24-34{ }^{\circ} \mathrm{C}$ (Mean $=30.1{ }^{\circ} \mathrm{C} \pm 6.9 \mathrm{SD}$ ) (Table 1). When heated by the sun, bare tree limbs and trunks can also have thermal signatures in this range, and therefore sometimes gave false positives. For this reason, animals were most reliably detected in the canopy during the night or early morning.

The thermal sensor was able to detect animals in the top few meters of the canopy depending on the thickness of the canopy. Animals on the ground or in the middle canopy were undetectable, based on tests with humans, which completely disappeared from view of the thermal sensor when the moved from an open area into the forest. The FLIR thermographic isolines calibrated using mammal external temperature ranges greatly enhanced the detectability of canopy mammals by increasing their contrast against the ambient background temperature of the rainforest (Figure 3). A combination of manual operator control and autonomous imagery collection enabled wildlife surveys to be conducted in tandem with habitat mapping surveys. 

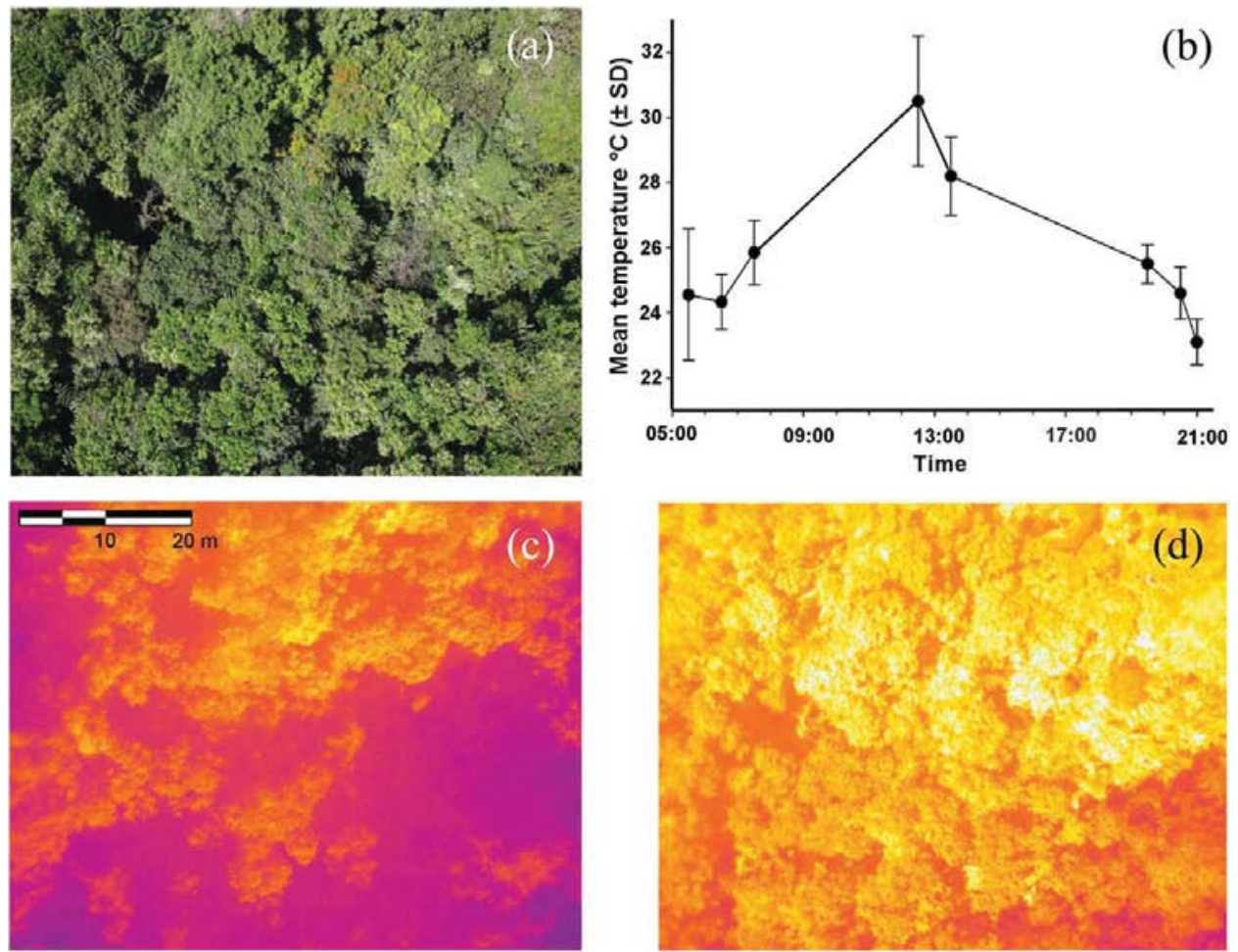

Temperature $\left({ }^{\circ} \mathrm{C}\right)$
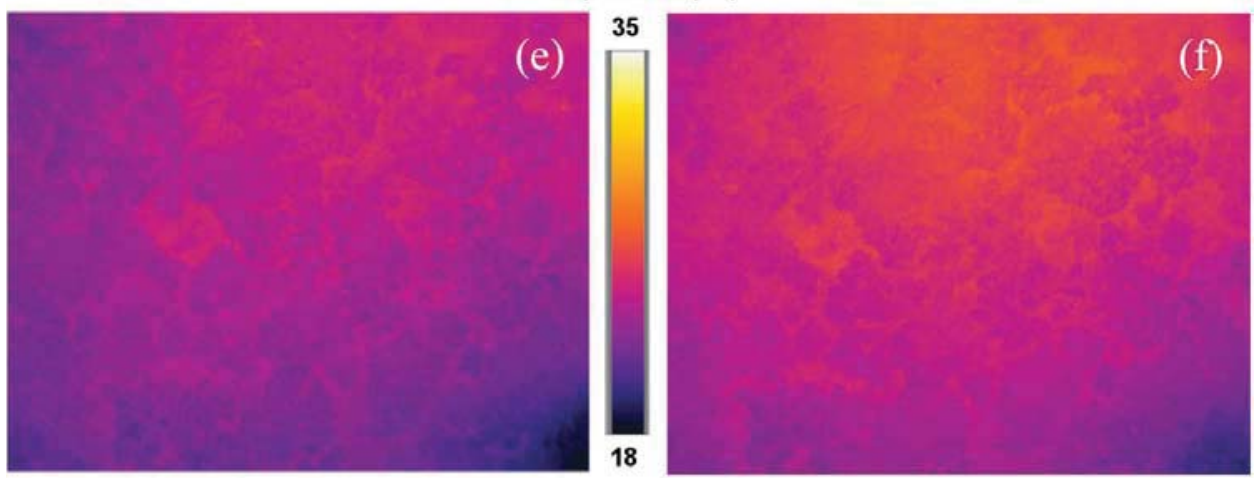

Figure 2. Color photograph (a) of the rainforest canopy on Barro Colorado Island, Panama and graph (b) of canopy temperatures captured by drone on 23 February 2018 using a series of thermal infrared images taken at different times of the day. Example thermal images are shown from 5:30 (c), 12:30 (d), 18:30 (e), and 20:30 (f).

Flying the drone at high elevations (> $100 \mathrm{~m}$ ) enabled a wider area to be surveyed in a shorter period of time than at lower elevations, but this benefit came at the expense of thermal sensor resolution and canopy animal detectability. Commercially available thermal imagery sensors for drones such as the Zenmuse model are currently low-resolution compared with visual cameras so the level of discernable detail dropped off steeply $>100 \mathrm{~m}$ altitude above the canopy. Flying at lower altitudes $(<50 \mathrm{~m})$ enabled the capture of higher resolution thermal imagery with an associated increase in animal detectability and likelihood of identifying the species. However, flying at lower altitudes required longer flight times to survey the same area and also increased the risk that the drone would disturb animals. Reducing the disturbance of animals is important not only to have less impact on the animal population, but also because animals that moved away from the drone by going towards the ground disappeared from the thermal imagery sensor as leaves blocked their thermal profile. 
Table 1. Differences between the ambient background temperature $\left({ }^{\circ} \mathrm{C}\right)$ of the rainforest and the temperature of 19 canopy animals measured by the drone thermal infrared sensor during different times of the day. The mean animal temperature of the animals was $30.1^{\circ} \mathrm{C}( \pm 6.9 \mathrm{SD})$ and the mean difference between animal thermal profiles and the environment was $5.5^{\circ} \mathrm{C}( \pm 4.3 \mathrm{SD})$. The extremely high temperature of the howler monkeys in the afternoon is probably due to the heating of their black fur by the sunshine and may not be representative of other species.

\begin{tabular}{|c|c|c|c|c|}
\hline Date \& Time & Species & $\begin{array}{c}\text { Mean environment } \\
\text { temperature }\left({ }^{\circ} \mathrm{C}\right)\end{array}$ & $\begin{array}{c}\text { Animal } \\
\text { temperature }\left({ }^{\circ} \mathrm{C}\right)\end{array}$ & $\begin{array}{c}\text { Temperature } \\
\text { difference }\left({ }^{\circ} \mathrm{C}\right)\end{array}$ \\
\hline 21 February 2018 15:08 & Howler monkey & 32.1 & 53.8 & 21.7 \\
\hline 21 February 2018 15:08 & Howler monkey & 31.9 & 42.1 & 10.2 \\
\hline 22 February 2018 6:43 & Howler monkey & 24.6 & 29.0 & 4.4 \\
\hline 22 February 2018 6:43 & Howler monkey & 24.3 & 26.9 & 2.6 \\
\hline 22 February 2018 6:43 & Howler monkey & 24.5 & 28.3 & 3.8 \\
\hline 22 February 2018 7:16 & Howler monkey & 21.7 & 26.9 & 5.2 \\
\hline 22 February 2018 7:16 & Howler monkey & 18.3 & 23.5 & 5.2 \\
\hline 22 February 2018 7:16 & Howler monkey & 16.7 & 25.2 & 8.5 \\
\hline 22 February 2018 7:16 & Howler monkey & 21.6 & 24.5 & 2.9 \\
\hline 22 February 2018 7:16 & Howler monkey & 21.7 & 28.7 & 7.0 \\
\hline 23 February 2018 20:38 & Kinkajou & 24.9 & 29.1 & 4.2 \\
\hline 24 February 2018 6:56 & Howler monkey & 22.7 & 25.3 & 2.6 \\
\hline 24 February 2018 19:44 & Kinkajou & 27.2 & 31.5 & 4.3 \\
\hline 24 February 2018 19:44 & Kinkajou & 27.5 & 31.7 & 4.2 \\
\hline 24 February 2018 19:44 & Kinkajou & 27.6 & 31.3 & 3.7 \\
\hline 25 February 2018 6:38 & Spider monkey & 24.6 & 26.6 & 2.0 \\
\hline 25 February 2018 6:46 & Kinkajou & 22.4 & 25.9 & 3.5 \\
\hline 25 February 2018 7:10 & Spider monkey & 24.7 & 28.6 & 3.9 \\
\hline 25 February 2018 7:11 & Spider monkey & 28.2 & 33.5 & 5.3 \\
\hline
\end{tabular}

The noise of the drone is a primary disturbance to wildlife, and this decreases with distance, becoming mostly inaudible to human hearing above $100 \mathrm{~m}$. Animals did not seem to be disturbed when our drone was $>40 \mathrm{~m}$ above the canopy, and they were variable in their response when it was $<40 \mathrm{~m}$. Kinkajous exhibited no observable reaction but some howler monkeys alarm-called and moved lower into the canopy. Flying the drone in darkness when only its small LED navigation lights were visible may have also helped reduced animal responses compared to flying in daylight.

Flying at high speeds $>6 \mathrm{~m} \mathrm{~s}^{-1}$ enabled a greater area to be surveyed in a shorter period than at lower speeds but this also reduced detectability of canopy animals. Although we did not conduct empirical comparisons of flight parameters on our ability to detect animals, we were able to compare sensor capabilities, drone operational parameters and observations of animal behavioral responses to conclude that a flight height of $80-100 \mathrm{~m} \mathrm{AGL}$ with flight speeds of $3 \mathrm{~m} \mathrm{~s}^{-1}$ provided an optimal mix of high animal detectability and large survey area coverage with minimal animal disturbance. At $100 \mathrm{~m} \mathrm{AGL}$ the thermal sensor footprint covered $3,500 \mathrm{~m}^{2}$ per image so a total flight time of 25 minutes at $3 \mathrm{~m} \mathrm{~s}^{-1}$ could cover an area of around 8 hectares.

Although the pixel resolution of the thermal imaging sensor was low, an experienced biologist could identify and differentiate canopy animal species from the thermal videos based on their size, morphology and distinctive movement behaviors. Drone surveys conducted during the morning enabled the use of a high-resolution visual RGB sensor, which provided additional information for identifying animals detected by the thermal sensor (Figure 3, supplementary material Video-2). 


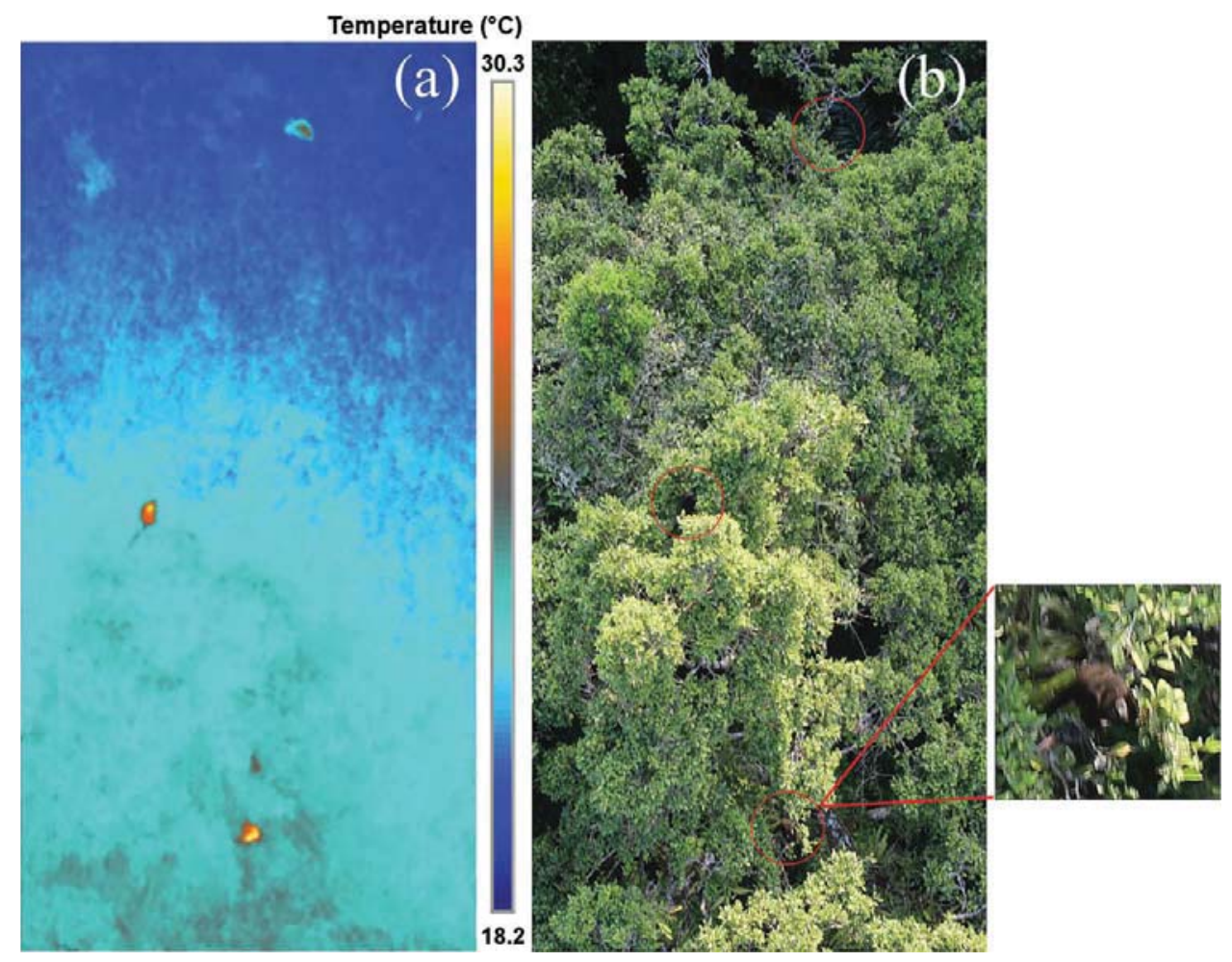

Figure 3. Radiometric image (a) captured by the infrared sensor attached to the drone flying at $100 \mathrm{~m}$ altitude showing white hotspots that highlight the warmer thermal signatures of seven howler monkeys in the rainforest canopy of Barro Colorado Island, Panama. The same site captured by a $51 \mathrm{MP}$ visual camera (b) at the same time with the locations of the monkeys indicated by red circles and an inset close-up image of one of the monkeys.

Our comparison between traditional ground-based surveys and aerial surveys of rainforest wildlife showed that an experienced biologist walking a trail can detect and identify many more animals than a drone across the same area. The biologist detected a total of 14 canopy animals compared to the 5 canopy animals detected by the drone (Figure 4). However, the drone was able to detect two animals that the biologist missed and was able to quickly cover areas off-trail that would be difficult to access on foot.

\section{Discussion}

Rainforest canopies are one of the least explored habitats on earth because they are difficult to access, making canopy animals challenging to observe. Studying canopy animals is particularly problematic because they are difficult to see from ground-based observers and impossible to follow when using traditional climbing techniques (i.e. towers or ropes). Drone mounted thermal sensors offer a highly mobile solution to survey canopies, and have the potential detect warm-blooded animals despite their camouflaged appearance. Our tests show that this tool can detect canopy animals from above, and observe them for short periods, but that there are still substantial logistical and technological limitations that restrict the utility of drone-mounted thermal sensors for these surveys today. These challenges include difficulty in detecting animals during the day, limits on identifying animals at night, and logistical constraints on equipment performance and importation. 


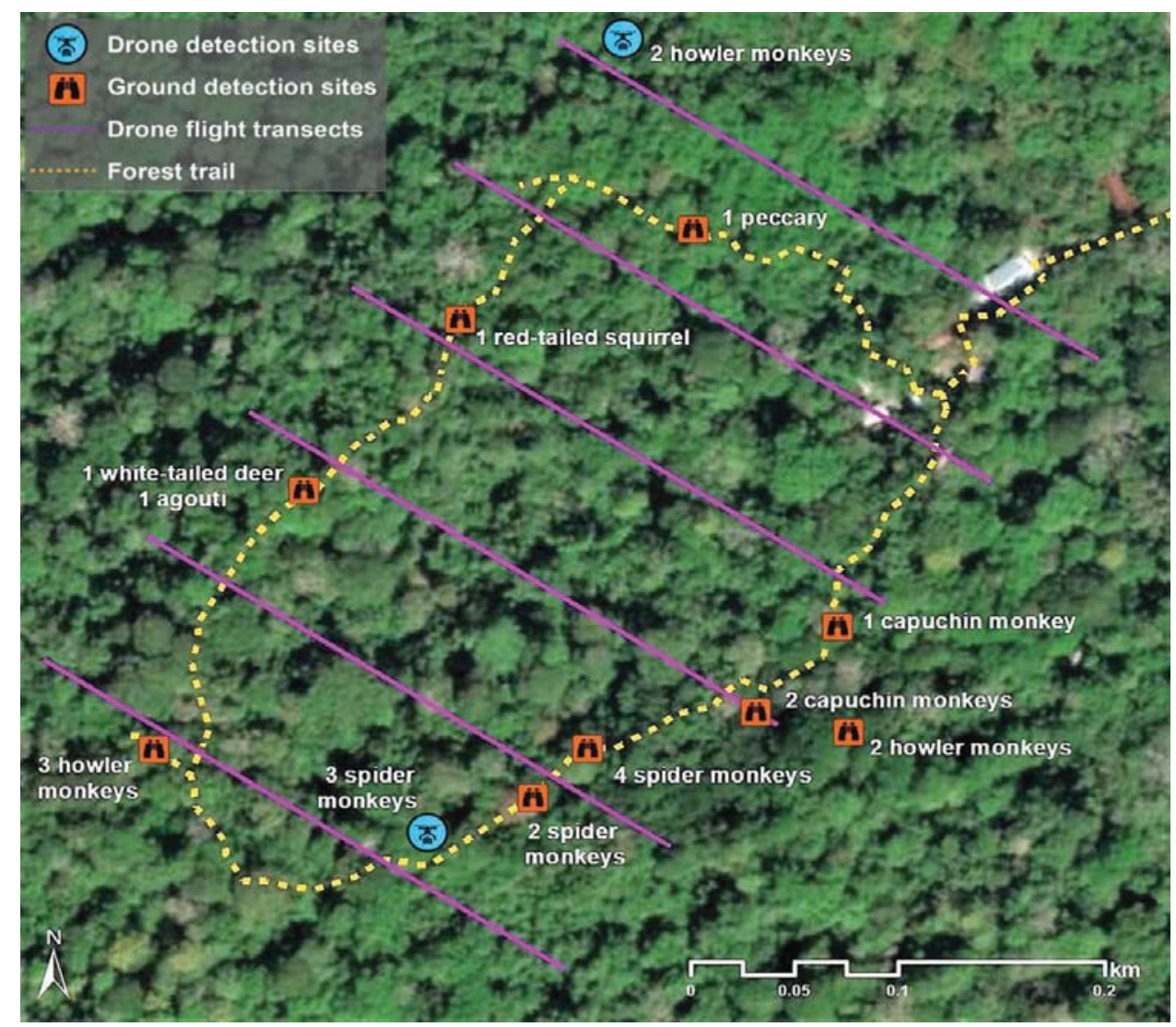

Figure 4. Results of a pilot study comparing the traditional ground-based method of surveying rainforest mammals conducted by a biologist with binoculars walking a $1.5 \mathrm{~km}$ forest trail versus a survey conducted across the same 12-hectare area flown by the drone along contiguous transects spaced $80 \mathrm{~m}$ apart. Surveys were conducted simultaneously at dawn over $\sim 35$ minutes for two consecutive days. The biologist detected 18 animals to the drone's 5, although the drone was able to detect animals that the biologist missed.

\subsection{Canopy survey results}

Thermal sensors are most useful for detecting warm-blooded animals in cooler and drier environments (Mulero-Pázmány et al. 2014) but have seen less application in the moist tropics. Our drone-based thermal sensor was effective at detecting canopy mammals at night and in the early morning when the animal's body temperature was typically at least $3^{\circ} \mathrm{C}$ warmer than the surrounding vegetation (Table 1), matching suggestions for the timing of surveys of other habitats (Mulero-Pázmány et al. 2014; Witczuk et al. 2017). However, the forest canopy temperature increased rapidly once heated by direct sunlight, resulting in a heterogeneous thermal background that overlapped with typical animal body temperatures, making it difficult to distinguish an endothermic animal from a sun-heated tree branch (Figure 2). The thermal sensor was effective at detecting canopy animals in the early morning, before the sun rose high enough to shine directly on tree branches, suggesting that daytime performance might be better on cloudy days.

Detection of animals was limited to those in direct line-of-sight to the sensor since their thermal signature was blocked by leaves once they descended below the top few meters of crown of the tree. Furthermore, the thermal views of animals, and humans, on the ground 
beneath the rainforest canopy were so completely blocked by leaves that no sign of them was visible, even when we knew where to look (i.e. when a person walked into the forest). Although aerial surveys of large mammals with thermal sensors have been effective in temperate deciduous and coniferous forests (Witczuk et al. 2017), we conclude that the closed canopy of mature tropical rainforests reduce the visibility of terrestrial animals so completely that there is little prospect for this approach. Indeed, most of the arboreally locomoting monkeys seen by our human observer were missed by the drone (Figure 4), presumably because they were in the midstory and thus obscured from view.

Similar to findings reported by Goodenough et al. (2018), we found that identifying animals to the species level from static thermal imagery alone is difficult. However, the thermal video of moving animals provided additional clues about how the animal climbed through the forest that could help domain experts distinguish species (Figure 1). Compared to typical color (RGB) cameras, thermal sensors are low resolution (i.e. ours was $640 \times 512$ pixels). Improved thermal sensor resolution would improve our ability to recognize species, and also allow detection of smaller animals from higher flight heights (Witczuk et al. 2017). Because our system had a high-resolution color camera paired with the thermal imagery we were able to capture visual records of the same animals detected by their thermal signature (Figure 3). These color pictures aided in species identification, and also highlighted how difficult it can be to initially detect animals without the aid of a thermal sensor, as we could only locate the monkeys in Figure $3 b$ by using the thermal imagery as a reference. Identifying species at night remains problematic, especially diurnal species like coatis or monkeys that roost in the treetops at night and thus wouldn't be seen moving from branch to branch. Future development of drone-mounted IR spotlights, or color flash photography, would help capture a higher resolution image of the animal needed to identify the species. These illuminators could probably be triggered by a machine learning algorithm trained to recognize the conspicuous heat signatures of animals against the cool night canopy (Lhoest et al. 2015; Longmore et al. 2017).

We found that canopy animals were not highly sensitive to the presence of the drone when flown at higher altitudes, in line with the review by Chabot and Bird (2015), who conclude that drones result in little to no wildlife disturbance if they are operated sensibly and at appropriate altitudes. Indeed, it is possible that drones flying at high altitudes could present less disturbance to animals than traditional survey methods, such as full-sized aircraft or ground-based field crews. Likewise, drones with thermal imaging sensors are probably less of a disturbance to nocturnal animals than survey methods that use constant spotlighting to detect eye shine. We demonstrated the ability of the drone to conduct short focal follows of canopy animals by following howler and spider monkey troops for $\sim 5$ minutes. However, drone-based follows of focal animals are limited by the risk of disturbance, the trade-off between increased flight height and reduced sensor resolution, and the restriction of drone flight times to periods < 30 minutes with existing battery capacities. Furthermore, it is likely that animals would be lost from view when they descend into the midstory of the canopy. Thus, while behavioral observations of canopy animals from a drone are possible, they are not practical. 


\subsection{Logistical hurdles}

The logistics of flying drones over natural areas are much more complicated than walking a trail with binoculars, and this further detracts from the potential for this method in real world situations. The first challenge is that international travel with drones can be difficult given restrictions on transporting high-power lithium batteries and the expense of shipping larger packages. These rules can also vary from country to country, for example, the USA Federal Aviation Authority currently allows unlimited batteries of up to $100 \mathrm{kwh}$ to be brought on commercial passenger flights as carryon luggage but restricts higher capacity batteries to two per person, while Panama airports restrict the personal transportation of all high-capacity lithium batteries on flights. High-end thermal imaging sensors may also be categorized as export restricted with government authorization needed to transport them to certain countries.

Once in country there are additional complications associated with local permits to fly drones. Regulations often require that aircraft must be within sight of the pilot at all times and forbid flying after dark, thus researchers must apply or special exemptions for flights to cover larger areas on auto-pilot, or to use the thermal sensor after dark, when it is most effective. Once at the field site there are additional limitations on the areas that can be surveyed based on suitable take-off and landing sites, line-of-sight from the pilot given the surrounding terrain, and the flight time of the aircraft. While multi-rotor copter crafts can take off and land in smaller areas, their flight time (typically 20-30min) is less than typical fixed wing planes (typically $40-120 \mathrm{~min})$, which require longer landing strips $(\sim 200 \mathrm{~m})$. The use of vertical takeoff and landing capabilities for fixed wing craft would help address these limitations. Flight plans need to also consider biases introduced through resighting the same individuals in subsequent surveys by standardizing routes and using appropriate statistical methods for analyzing aerial survey data (Pollock et al. 2006).

Larger drones are sometimes needed to carry multiple sensors, but these are also more difficult to fly from inside the forest and carry to remote field sites. Drones with advanced flight and sensor capabilities require a high initial capital investment related requires training in operation and maintenance. Operating an expensive and complicated drone in darkness requires additional experience and confidence. Finally, flying opportunities can be severely restricted by inclement weather common to tropical rainforests such as rain, wind $\left(>10 \mathrm{~m} \mathrm{~s}^{-1}\right)$, fog, and mists.

After the flights are complete, the processing of drone images is another challenge. Although the detection of wildlife in thermal sensors could probably be automated (Lhoest et al. 2015; Longmore et al. 2017), it presently still requires manual processing of imagery data. Processing and storing these data require forethought into the appropriate computer hardware, which might not be easily accessible at remote field sites. For example, in our work, the combination of our thermal imagery and 50.6 megapixel color pictures resulted in more than 5 GB of data for every 20 minutes of flight time. Stitching large amounts of high-resolution sensor data into composite mosaics also requires expensive software and may take many hours to complete. 


\section{Conclusion}

Our study represents the first test of drone-mounted thermal imagery to survey tropical rainforest canopy mammals. We found the tool effective in detecting larger canopy animals at night and in the early morning, but also identified a number of limitations that restrict its utility and practicality as a wildlife survey tool today. Traditional groundbased surveys outperformed our drone surveys in a head-to-head comparison, although the aircraft did detect some animals missed by the human observer. The high-altitude perspective and rapid flight speeds of drones, combined with the high detectability of animals from thermal imagery, offer distinct advantages for studying canopy mammals and we hope continued refinement of hardware and software will reduce the limitations of the method and eventually make drone-based surveys of canopy animals a reality.

\section{Acknowledgments}

Andreas Schuerkmann, Megan Owen, Nick Pilfold, Tony Long, Ronald Swaisgood, Linnea Havmøller, Rasmus Havmøller, Smithsonian Tropical Research Institute, Packard Foundation Fellowship 2016-65130, NSF BCS 1440755, NSF SBE 1713797, Northrop Grumman Corporation, FLIR Systems, Inc., DSLR Pros

\section{Disclosure statement}

No potential conflict of interest was reported by the authors.

\section{Funding}

This work was supported by the National Science Foundation [BCS 1440755,SBE 1713797]; Packard Foundation Fellowship [2016-65130]

\section{References}

Bowler, M. T., M. W. Tobler, B. A. Endress, M. P. Gilmore, and M. J. Anderson. 2016. "Estimating Mammalian Species Richness and Occupancy in Tropical Forest Canopies with Arboreal Camera Traps." Remote Sensing in Ecology and Conservation 3: 1-12. doi:10.1002/rse2.35.

Chabot, D., and D. M. Bird. 2015. "Wildlife Research and Management Methods in the 21st Century: Where Do Unmanned Aircraft Fit In?" Journal of Unmanned Vehicle Systems 3 (4): 137-155. doi:10.1139/juvs-2015-0021.

Chretien, L. P., J. Theau, and P. Menard. 2016. "Visible and Thermal Infrared Remote Sensing for the Detection of White-Tailed Deer Using an Unmanned Aerial System." Wildlife Society Bulletin 40: 181-191. doi:10.1002/wsb.629.

Croon, G. W., D. R. McCullough, C. E. Olson, and L. M. Queal. 1968. "Infrared Scanning Techniques for Big Game Censusing." The Journal of Wildlife Management 32 (4): 751. doi:10.2307/3799549.

Gonzalez, L., G. Montes, E. Puig, S. Johnson, K. Mengersen, and K. Gaston. 2016. "Unmanned Aerial Vehicles (Uavs) and Artificial Intelligence Revolutionizing Wildlife Monitoring and Conservation." Sensors 16 (1): 97. Multidisciplinary Digital Publishing Institute. doi:10.3390/s16010097.

Goodenough, A. E., W. S. Carpenter, L. MacTavish, C. Theron, M. Delbridge, and A. G. Hart. 2018. "Identification of African Antelope Species: Using Thermographic Videos to Test the Efficacy of Real-Time Thermography." African Journal of Ecology. doi:10.1111/aje.12513. 
Gregory, T., F. C. Rueda, J. Deichmann, J. Kolowski, and A. Alonso. 2014. "Arboreal Camera Trapping: Taking a Proven Method to New Heights." Edited by D. Fisher. Methods in Ecology and Evolution 5 (5): 443-451. doi:10.1111/2041-210X.12177.

Haroldson, B. S., E. P. Wiggers, J. Beringer, L. P. Hansen, and J. B. McAninch. 2003. "Evaluation of Aerial Thermal Imaging for Detecting White-Tailed Deer in a Deciduous Forest Environment." Wildlife Society Bulletin 31: 1188-1197. WileyWildlife Society. doi:10.2307/3784466.

Hodgson, J. C., S. M. Rowan Mott, T. T. Baylis, S. W. Pham, A. D. Kilpatrick, R. R. Segaran, I. Reid, A. Terauds, and L. P. Koh. 2018. "Drones Count Wildlife More Accurately and Precisely than Humans." Methods in Ecology and Evolution (February). Wiley/Blackwell (10.1111). doi:10.1111/ 2041-210X.12974.

Kays, R. W., and A. Allison. 2001. "Arboreal Tropical Forest Vertebrates: Current Knowledge and Research Trends." Plant Ecology 153 (1/2): 109-120. doi:10.1023/A:1017585622940.

Lhoest, S., J. Linchant, S. Quevauvillers, C. Vermeulen, and P. Lejeune. 2015. "How Many Hippos (Homhip): Algorithm for Automatic Counts of Animals with Infra-Red Thermal Imagery from UAV." International Archives of the Photogrammetry, Remote Sensing and Spatial Information Sciences - ISPRS Archives 40: 355-362. doi:10.5194/isprsarchives-XL-3-W3-355-2015.

Longmore, S. N., R. P. Collins, S. Pfeifer, S. E. Fox, M. Mulero-Pázmány, F. Bezombes, A. Goodwin, M. De Juan Ovelar, J. H. Knapen, and S. A. Wich. 2017. "Adapting Astronomical Source Detection Software to Help Detect Animals in Thermal Images Obtained by Unmanned Aerial Systems." International Journal of Remote Sensing 38 (8-10): 2623-2638. doi:10.1080/ 01431161.2017.1280639.

Lowman, M. D. 2009. "Canopy Research in the Twenty-First Century: A Review of Arboreal Ecology." Tropical Ecology 50 (1): 125-136.

Mulero-Pázmány, M., R. Stolper, L. D. Van Essen, J. J. Negro, and T. Sassen. 2014. “Remotely Piloted Aircraft Systems as a Rhinoceros Anti-Poaching Tool in Africa." PLoS ONE 9 (1): e83873. doi:10.1371/journal.pone.0083873.

Pollock, K. H., H. D. Marsh, I. R. Lawler, and M. W. Alldredge. 2006. "Estimating Animal Abundance in Heterogeneous Environments: An Application to Aerial Surveys for Dugongs." Journal of Wildlife Management 70 (1): 255-262. doi:10.2193/0022-541x(2006)70[255:eaaihe]2.0.co;2.

Potvin, F., and L. Breton. 2005. "Testing 2 Aerial Survey Techniques on Deer in Fenced Enclosures — Visual Double-Counts and Thermal Infrared Sensing." Wildlife Society Bulletin 33 (1): 317-325. doi:10.2193/0091-7648(2005)33[317:FTFTAS]2.0.CO;2.

Sampaio, R., A. P. Lima, W. E. Magnusson, and C. A. Peres. 2010. "Long-Term Persistence of Midsized to Large-Bodied Mammals in Amazonian Landscapes under Varying Contexts of Forest Cover." Biodiversity Conservation 19: 2421-2439. doi:10.1007/s10531-010-9848-3.

Seymour, A. C., J. Dale, M. Hammill, P. N. Halpin, and D. W. Johnston. 2017. "Automated Detection and Enumeration of Marine Wildlife Using Unmanned Aircraft Systems (UAS) and Thermal Imagery." Scientific Reports 7: 45127. doi:10.1038/srep45127.

Thapa, G. J., K. Thapa, R. Thapa, S. R. Jnawali, S. Wich, L. P. Poudyal, and S. Karki. 2018. "Counting Crocodiles from the Sky: Monitoring the Critically Endangered Gharial (Gavialis Gangeticus) Population with an Unmanned Aerial Vehicle (UAV)." Journal of Unmanned Vehicle Systems 6: 71-82. doi:10.1139/juvs-2017-0026.

van Andel, A. C., S. A. Wich, C. Boesch, L. P. Koh, M. M. Robbins, J. Kelly, and H. S. Kuehl. 2015. "Locating Chimpanzee Nests and Identifying Fruiting Trees with an Unmanned Aerial Vehicle." American Journal of Primatology 77 (10): 1122-1134. doi:10.1002/ajp.22446.

Wich, S., D. Dellatore, M. Houghton, R. Ardi, and L. P. Koh. 2016. "A Preliminary Assessment of Using Conservation Drones for Sumatran Orang-Utan (Pongo Abelii) Distribution and Density." Journal of Unmanned Vehicle Systems 4 (1): 45-52. doi:10.1139/juvs-2015-0015.

Witczuk, J., S. Pagacz, A. Zmarz, and M. Cypel. 2017. "Exploring the Feasibility of Unmanned Aerial Vehicles and Thermal Imaging for Ungulate Surveys in Forests - Preliminary Results." International Journal of Remote Sensing 1-18. doi:10.1080/01431161.2017.1390621. 